\title{
Genetic professionals' reports of nondisclosure of genetic risk information within families
}

\author{
Angus Clarke*,1,13, Martin Richards ${ }^{2,13}$, Lauren Kerzin-Storrar ${ }^{3,13}$, Jane Halliday ${ }^{4,13}$, Mary \\ Anne Young ${ }^{5}$, Sheila A Simpson ${ }^{6}$, Katie Featherstone ${ }^{7}$, Karen Forrest ${ }^{8}$, Anneke Lucassen ${ }^{9}$, \\ Patrick J Morrison ${ }^{10}$, Oliver WJ Quarrell ${ }^{11}$, Helen Stewart ${ }^{12}$ and collaborators
}

${ }^{1}$ Institute of Medical Genetics, University Hospital of Wales, Heath Park, Cardiff CF14 4XN, UK; ${ }^{2}$ Centre for Family Research, Free School Lane, Cambridge CB2 3RF, UK; ${ }^{3}$ Regional Genetic Service and Academic Unit of Medical Genetics, St Mary's Hospital, Hathersage Rd, Manchester M13 OJH, UK; ${ }^{4}$ Public Health Genetics (on behalf of Genetic Health Services Victoria), Murdoch Children's Research Institute, Victoria, Australia; ${ }^{5}$ Family Cancer Centre, Peter MacCallum Cancer institute, Victoria 8006, Australia; ${ }^{6}$ Department of Medical Genetics, University of Aberdeen, School of Medicine, Polwarth Building, Aberdeen AB25 2ZD, UK; ${ }^{7}$ CESAGen, Cardiff School of Social Sciences, Cardiff University, 6 Museum Place, Cardiff, UK; ${ }^{8}$ Department of Public Health, University of Aberdeen, School of Medicine, Polwarth Building, Aberdeen AB25 2ZD, UK; ${ }^{9}$ Wessex Clinical Genetics Service, The Princess Anne Hospital, Coxford $R d$. ., Southampton SO16 5YA, UK; ${ }^{10}$ Department of Medical Genetics, Belfast City Hospital Trust, Belfast BT9 $7 A B$, UK; ${ }^{11}$ North Trent Clinical Genetics Service, Blue Wing, Sheffield Children's NHS Trust, Western Bank, Sheffield S1O 2TH, UK; ${ }^{12}$ Department of Clinical Genetics, Churchill Hospital, Old Road, Oxford OX3 7LJ, UK

Patients attending genetic clinics are often the main gatekeepers of information for other family members. There has been much debate about the circumstances under which professionals may have an obligation, or may be permitted, to pass on personal genetic information about their clients but without their consent to other family members. We report findings from the first prospective study investigating the frequency with which genetics professionals become concerned about the failure of clients to pass on such information to their relatives. In all, 12 UK and two Australian regional genetic services reported such cases over 12 months, including details of actions taken by professionals in response to the clients' failure to disclose information. A total of 65 cases of nondisclosure were reported, representing $<1 \%$ of the genetic clinic consultations in the collaborating centres during the study period. These included 39 cases of the failure of parents not passing full information to their adult offspring, 22 cases where siblings or other relatives were not given information and four cases where information was withheld from partners including former and prospective partners. Professionals reported clients' reasons for withholding information as complex, more often citing concern and the desire to shield relatives from distress rather than poor family relationships. In most cases, the professionals took further steps to persuade their clients to make a disclosure but in no instance did the professional force a disclosure without the client's consent. European Journal of Human Genetics (2005) 13, 556-562. doi:10.1038/sj.ejhg.5201394

Published online 16 March 2005

\footnotetext{
${ }^{*}$ Correspondence: Professor A Clarke, Department of Medical Genetics, University Hospital of Wales, Health Park, Cardiff CF14 4XN, UK. Tel: + 442920744 057; Fax: + 442920747603 ; E-mail: clarkeAJ@Cardiff.ac.uk. Collaborators: Ahmad A, West Midlands Regional Clinical Genetics Unit, Birmingham Women's Hospital, Edgbaston, Birmingham B15 2TG, UK. Brennan P, Teesside Genetics Unit, James Cook University Hospital, Marton Rd., Middlesborough TS4 3BW, UK.

Lynch SA, formerly Department of Human Genetics, International Centre for Life, Newcastle upon Tyne, UK (now National Centre for Medical
}

Genetics, Our Lady's Hospital for Sick Children, Crumlin, Dublin 12, Eire). Wiles V, Department of Medical Genetics, Addenbrookes NHS Trust, Hills Rd., Cambridge CB2 2QQ, UK.

Zukowska-Wilcocks A, Yorkshire Regional Genetic Service, Department of Clinical Genetics, Ashley Wing, St James University Hospital, Leeds LS9 7TF, UK

${ }^{13}$ These authors contributed equally to this work.

Received 23 September 2004; revised 20 January 2005; accepted 21 January 2005 


\section{Keywords: confidentiality; disclosure; genetic information; genetic counselling}

\section{Introduction}

Patients attending genetic clinics are often the main gatekeepers of information for other family members. ${ }^{1}$ However, patients do not always pass on this information to relatives. $^{2-5}$ This can be important because these relatives may then be denied the opportunity to make informed health choices, for example, in relation to reproduction or the management of the risks of disease. ${ }^{6-11}$ Furthermore, there may be other family members, not related by blood, who could benefit from the knowledge. ${ }^{6,9,10,12}$ Nondirectiveness has long been held to be a central principle of genetic counselling, ${ }^{13}$ despite doubts about whether this is always possible in practice ${ }^{14}$ or appropriate to all genetic counselling situations. ${ }^{15}$ While disclosure without consent would violate the client's privacy, $^{16}$ any steps taken to persuade or encourage a counsellee to disclose information to another family member would clearly amount to directive counselling.

\section{Family communication}

Empirical research suggests that family communication about genetic risk is not always straightforward. ${ }^{17-21}$ Although clients may acknowledge their obligation to pass on relevant genetic information to family members, this may be balanced against a desire not to cause anxiety or alarm. ${ }^{22-24}$ Difficult issues may arise about the timing and content of disclosure and the judgement as to who 'needs to know', which, of course, may depend upon how the disorder in question is (thought to be) inherited. ${ }^{4,9,20,25}$ While communication of genetic information may follow the usual family channels, ${ }^{25}$ practical barriers such as geographical distance, family rifts, divorce, separation, adoption and large age gaps between siblings may impede communication. ${ }^{17,22,23}$ Complex family dynamics may make it more difficult to convey information to siblings than adult children. ${ }^{26}$ Communication may be influenced by patterns of mutual surveillance for signs of disease, and moral scrutiny and judgement as well as beliefs about inheritance and disease. ${ }^{19,27-29}$ In addition, information provided in genetic counselling may be imperfectly understood, leaving genetic professionals and family members with different views because of their different understandings of the risks and benefits of disclosure.

\section{Ethical and practitioner issues}

The failure of a client to disclose important information to relatives will raise ethical issues for the professionals involved, ${ }^{23,30}$ but professional disclosure without consent could undermine trust in the counselling process. ${ }^{16}$ To address this issue, profession-led guidelines in the UK, Australia, and the USA recommend an approach which emphasises the primary importance of maintaining confidentiality but which permits disclosure by health profes- sionals without the patient's consent in 'exceptional circumstances' ${ }^{8,31,32}$ These guidelines provide a framework within which clinicians can work but there has been no specific legislation regulating the flow of genetic information in families. ${ }^{33-35}$ An inquiry by the Australian Law Reform Commission and the Australian Health Ethics Committee $^{6}$ concluded that privacy legislation inappropriately constrains health professionals' decisions about the disclosure of clinically relevant information to genetic relatives and that this situation should be remedied by legislation and the modification of professional guidelines, but this has been criticised in a response by the Human Genetics Society of Australasia as promoting, or perhaps making obligatory, forced disclosure by professionals. While English law underlines a strict interpretation of a doctor's duty of confidentiality based on an individualistic perception of patient autonomy and an overriding utilitarian principle of prevention of harm to others, it has been argued that family members deserve more legal recognition and that the current individualistic legal approach to confidentiality is too narrow. ${ }^{36}$

The attitudes of patients and clinicians towards the breaking of confidentiality may vary according to the cultural context ${ }^{1,37}$ and the nature of the health care system. ${ }^{10,38}$ Hypothetical studies suggest that many professionals would disclose information to family members without consent under some circumstances. ${ }^{39,40}$ Others have argued that the obligation to disclose to relatives is not a question of 'rights' but rather of family responsibilities $^{41,42}$ and some caution that pressure to disclose genetic information may undermine family values and disrupt relationships. ${ }^{43}$

Little is known about the frequency with which these ethical problems arise within everyday clinical genetics practice. ${ }^{44}$ Retrospective surveys of members of the American Society of Human Genetics and/or American College of Medical Genetics and National Society of Genetic Counsellors found that a quarter of the clinical geneticists and half the counsellors reported having had patients who refused to inform family members at risk. While a significant minority seriously considered informing relatives without consent only a single geneticist and a single counsellor reported having done so. Genetic counsellors reported that emotional issues were the major reason not to disclose without consent, while clinical geneticists more often cited patient confidentiality and their own legal liability. ${ }^{45,46}$

An interview-based study of US patients affected with a variety of genetic or nongenetic conditions found that their views and experiences of disclosure within families did not differ between genetic and nongenetic conditions. The authors suggested that a focus specifically on genetic 
information, treating this as a special case, may therefore be unwarrented. ${ }^{47}$

\section{Aims of Study}

In order to inform discussion about confidentiality and family communication in the context of genetics, we need to know more about what actually happens in clinical practice. The aim of this prospective collaborative study was to collect information on the frequency with which clinical geneticists and genetic counsellors become concerned about the refusal of clients to disclose important genetic information to their relatives, the circumstances in which these situations arise and the actions then taken by the genetic health professionals.

\section{Methods}

A total of 12 Regional Genetic Services in the UK and two in Australia agreed to collaborate in this study. Clinical geneticists and genetic counsellors in the UK centres provide a comprehensive genetic counselling service for adult (including cancer), paediatric and reproductive referrals for their population; the two Australian centres jointly provide a similar service, with one centre dealing with cancer genetics only. Ethics Committee approval was obtained for the collection of nonidentifiable information to be collected prospectively, without patient consent. Episodes of nondisclosure were collected over a 12-month period (commencing on a different date at each centre between October 2000 and July 2001). Nondisclosure was defined as: 'a situation in which a clinician believes (i) that a family member should disclose information to another family member because failure to do so could lead to potential harm for that relative and to her family members, but (ii) that this disclosure seems unlikely to take place.'

For each episode, details were recorded on the diagnosis, sex, age, ethnicity and genetic status of the proband, how the issue of nondisclosure arose in the clinic, the reasons for the nondisclosure as given to the professional by the proband, and the professional's response (any subsequent actions and/or ongoing concerns). Approximate annual consultation figures for the collaborating centres were also obtained to estimate the frequency of episodes of nondisclosure.

The cases were discussed between the UK collaborators and lead researchers at two meetings to ensure a common approach to the reporting of cases and to establish agreement on inclusion criteria. Separate discussions were conducted in person and by mail with the Australian contributors. After all cases were reported, the lead researchers identified common themes among cases, and these categories were refined after clarification with the collaborators. Follow-up data on cases were obtained in January 2003 (6-31 months after cases first reported).

\section{Results \\ Cases}

A total of 65 cases of nondisclosure were reported, which amounts to a very small proportion of the nearly 40000 genetic clinic consultations conducted annually in the collaborating centres. There was a wide range of Mendelian and chromosomal conditions represented but the conditions most commonly reported were Huntington's disease (HD), chromosome translocations and hereditary cancer syndromes (Table 1). These included 39 cases of the failure of parents to transmit full information to their adult offspring, 22 cases where siblings or other relatives were not given information and four cases where information was withheld from partners - including former and prospective partners.

Nondisclosure to adult offspring There were 39 cases where adult children were not given full information by their parents about the family's hereditary disorder. In half of these cases involving nondisclosure from parents to adult children, the genetic diagnosis had recently been confirmed or revised through molecular testing. There were three women affected with breast cancer, who did not intend to inform their adult daughters that a BRCA1 or BRCA2 mutation had been identified, and one male, who had predictive testing for a BRCA mutation while intending not to inform his adult daughter. There were 11 cases where a parent with a confirmed HD mutation (whether or not currently affected) and/or their spouse withheld knowledge of the diagnosis from their adult children. In one case, an affected man and his wife chose not to disclose nonpaternity to their adult children, who believed themselves to be at $50 \%$ risk of $\mathrm{HD}$. In two cases with an unfavourable result of an HD predictive test, the consultant indicated that they had told their children their test result but the children still believed they were at 25\% risk (rather than 50\%) when they subsequently and independently attended the genetic clinic. These cases were included in

Table 1 Approximate frequency of nondisclosure in consultations for different disorders

\begin{tabular}{|c|c|c|c|}
\hline & $\begin{array}{l}\text { Number of } \\
\text { cases }\end{array}$ & $\begin{array}{c}\text { Approximate } \\
\text { number of } \\
\text { disease } \\
\text { consultations } \\
\text { during study } \\
\text { period }\end{array}$ & $\begin{array}{l}\text { Frequency of } \\
\text { cases (\%) }\end{array}$ \\
\hline Huntington's disease & 24 & 3555 & 0.675 \\
\hline $\begin{array}{l}\text { Chromosome } \\
\text { translocations }\end{array}$ & 8 & 790 & 1.01 \\
\hline $\begin{array}{l}\text { Hereditary breast/ } \\
\text { ovarian or colorectal } \\
\text { cancer }\end{array}$ & 9 & 9914 & 0.0908 \\
\hline $\begin{array}{l}\text { Other Mendelian } \\
\text { conditions }\end{array}$ & 24 & Large & Small \\
\hline Total & 65 & 38677 & 0.168 \\
\hline
\end{tabular}


the study but, in such circumstances, it may be difficult to know whether it was the 'parents' who had failed to provide the information or the 'children' who had failed to appreciate it. This group of nondisclosers has also shown that significant life events can diminish the immediate importance of the genetic information: there was one case each of heroin addiction, imprisonment and major mental illness affecting the at-risk 'adult' children to whom full disclosure had not been made.

Nondisclosure to siblings and other relatives In all, 22 cases fell into this category. Eight involved a balanced chromosome translocation, including two where the consultant had been adopted and did not want to contact their biological family, although this was feasible. One patient with a confirmed colorectal cancer (HNPCC gene) mutation, felt unable to discuss this with their adult mentally handicapped sibling, and accepted the advice of the sibling's GP and carers not to pass on the genetic information. The patient therefore acquiesced in a decision made by health and social care professionals about the sibling, raising important issues about the welfare of those with intellectual disability cared for in our communities. One consanguineous couple would not inform their possible carrier siblings of their child's diagnosis, which entailed gender ambiguity. One HD mutation carrier declared an intention to emigrate without disclosing any information to their siblings, unaware of the family history or to their doctor. Another HD mutation carrier had for many years been the victim of extreme violence from their sibling and would not make contact for this reason. Two cases involved carriers of cystic fibrosis (CF), one male and one female, who were providing gametes for assisted conception and would not disclose their CF carrier status to relatives, who were unaware that a family member was undergoing fertility treatment.

Nondisclosure to partners In four cases, information was being withheld from partners or expartners. In one case, a pregnant woman was unaware of her partner's family history of HD. In two cases, parents (one mother and one father) would not disclose information about a genetic diagnosis in their child to an estranged expartner who could be at risk of having affected children. In one family, a young woman and her parents withheld information from her new husband about the risk of an autosomal recessive condition in the family.

\section{Professionals' reports of reasons for nondisclosure given by consultants}

When reporting episodes to this survey, our colleagues described the reasons given by their clients for not disclosing information to relatives. Most clients gave complex reasons for withholding information from relatives, more often citing concern and the desire to protect
Table 2 Professionals understandings of clients' reasons for nondisclosure

\begin{tabular}{lr}
\hline Reasons given (may be more than one per case) & $\begin{array}{c}\text { Number } \\
\text { of cases }\end{array}$ \\
\hline $\begin{array}{l}\text { Concern for relatives } \\
\text { Don't want to cause worry/anxiety } \\
\text { Believe relative 'couldn't cope' with information }\end{array}$ & $\begin{array}{r} \\
\text { Family dynamics }\end{array}$ \\
$\begin{array}{l}\text { Poor relationship/anger/resentment towards } \\
\text { relative(s) }\end{array}$ & 9 \\
$\begin{array}{l}\text { Not in contact with relatives (includes three } \\
\text { adoptees) }\end{array}$ & 9 \\
$\begin{array}{l}\text { Other family members are banning disclosure } \\
\text { Fear of adverse consequences }\end{array}$ & 3 \\
$\begin{array}{l}\text { Might disrupt marriage plans } \\
\text { Fears blame }\end{array}$ & 4 \\
$\begin{array}{l}\text { Responsibility } \\
\text { Doesn't want/feels unable to take responsibility }\end{array}$ & 5 \\
$\begin{array}{l}\text { Privacy (eg paternity, assisted conception) } \\
\text { Assumptions about relevance (eg wouldn't be } \\
\text { interested, aren't having children) } \\
\text { Better not to know }\end{array}$ & 8 \\
\hline
\end{tabular}

their relatives rather than poor family relationships (Table 2). The desire to avoid causing anxiety was the most frequently given reason for the decision not to disclose information. Many clients made their own judgements as to whether their relatives personally needed the information or could cope with it. Other frequently cited reasons were problematic family dynamics, including loss of contact, poor family relationships and fear that disclosure might disrupt a family member's marriage plans - there were three families with arranged marriages pending. In three further cases, it was another relative not the client - who was 'banning' disclosure. Five consultants feared being blamed if the information was disclosed, and eight felt unable or unwilling to take responsibility for informing relatives. Eight consultants did not want to inform their relatives because they felt it was better for them not to know about the genetic risk; five of these eight were still expressing strong emotion over learning about the genetic diagnosis themselves. For just six consultants was the issue of privacy given as the principal reason for failure to disclose.

\section{Professionals' actions}

In most cases, clinical geneticists and genetic counsellors reported that they 'took further steps to persuade the consultant to make a disclosure'. These steps included further discussion with the consultant, both to reinforce the professional's view that disclosure was important and to clarify the consultant's reasons for nondisclosure. Discussion took place at the first consultation in which 
the nondisclosure was identified, and again at follow-up contacts in clinic, by telephone or at home visits. Other actions included involving experienced colleagues in the discussions with the consultant and using written reminders in an effort to prompt disclosure.

While there were no reports in this series of genetics professionals disclosing information to relatives without the consultant's permission, there were several instances of active offers made to facilitate disclosure. These included enclosing copies of the summary letter with the suggestion that these be passed to relatives, and sending clients 'open letters' - including the offer of a genetic clinic appointment - which could be given to relatives.

\section{Discussion}

In this prospective study, clinically important episodes of nondisclosure within families were identified in less than $1 \%$ of all consultations. It may be that patients usually do disseminate important genetic information to their relatives, or genetics health professionals may be unaware of the extent to which communication within families does not happen. A collaborative study of this type, relying on a large number of professionals to report their subjective concerns, can only provide a rough estimate of the frequency of professional concern about nondisclosure. Professionals will undoubtedly vary in the attention they give to the issue of the dissemination of information to other family members; they will often not know whether family members actually do pass on information and there may or may not be follow-up to enquire as to whether this happens. Finally, some obstacles to the transmission of information may be less likely than others to be noted in such a survey. In particular, patterns of family communication that result in blocks to the passing of genetic information from parents to their (adult) children have been recognised for decades ${ }^{48}$ but such longstanding behavioural patterns may not be noted by professionals recording discrete episodes. Where parents know the results of genetic carrier tests on their children, for example, they may omit to pass on this information as the child matures, ${ }^{49,50}$ but it would be difficult to pinpoint an episode of nondisclosure. Despite these notes of caution, however, our figure is the first population-based estimate of such clinical episodes giving rise to professional concern.

Our exploration of clients' reasons for failure to disclose information was second hand, but it was of interest that the motivation appeared more commonly to be a reluctance to cause anxiety than poor family relationships. The nondisclosing clients were often making judgements as to whether a particular relative could cope with, or would want to be given, the information in question - parents in particular making these decisions on behalf of their (adult) children. The extent to which such explanations are post hoc justifications for the messenger's reluctance to be blamed for the 'bad news' is unclear, but considerations about the best interests of the potential recipient of the information are a consistent feature of accounts from other sources too. ${ }^{9,27}$ In only eight cases did the client take the general stance that it is better 'not to know' one's genetic predicament than to know it.

Nondisclosure rates vary between conditions with nondisclosure issues arising relatively frequently in HD families, often from a desire to protect family members from distressing knowledge in the absence of effective therapy. Studies of communication and decision-making in HD families have described how family members may reach decisions using rather different considerations than those adopted by professionals. ${ }^{51-53}$ Another factor contributing to the higher number of nondisclosure episodes reported in families with $\mathrm{HD}$ may relate to the greater number of contact hours between the professional and the consultant in this disease. The consequence may be a deeper understanding of the inter-relationships between the consultant and family, alerting professionals to the potential issue of nondisclosure. There may be less motivation to disclose risks in families carrying translocations where the risks of a liveborn child with a chromosomal aneuploidy may be small and the miscarriage of affected pregnancies may be interpreted as 'nature taking its course'. There may also be a greater wish for privacy in relation to lost pregnancies and the use of assisted conception or prenatal diagnosis. The particular problems in cancer families may arise because healthy, but at-risk individuals may be reluctant to ask affected individuals to provide a sample for analysis ${ }^{54}$ while the affected individuals may be reluctant to raise anxieties in their healthy relatives in the absence of a clear practical benefit. ${ }^{55}$

The duration of follow-up for the cases reported here has been variable but has certainly not been sufficient to let us draw any conclusions about long-term outcomes of reported episodes of nondisclosure. The diagnosis had recently been confirmed or revised in the light of molecular testing in more than half of the 28 cases involving nondisclosure by parents to their adult children, so disclosure may progress with time with the new test results acting as a catalyst.

There is no evidence from our study that geneticists or genetic counsellors are 'breaking confidentiality' when nondisclosure becomes apparent or is declared by the genetic counselling client, but they do regularly try to persuade clients to disclose relevant information within the family, sometimes quite actively. This policy of active persuasion, recommended by professional bodies, may be one of those contexts within genetic counselling where an adherence to the ethos of nondirectiveness would be inappropriate. ${ }^{56} \mathrm{~A}$ recent analysis of the current legal situation in USA has also concluded that professionals 
should encourage but not coerce the sharing of important health risk information by genetic counselling clients with their at-risk relatives. ${ }^{57}$

It has been argued that genetic information cannot by its very nature be private and should therefore not be bound by the usual professional codes of respect for confidentiality $^{15}$ - with genetic information generated about one individual being treated as essentially familial and therefore to be shared with other family members on a 'joint account' model $^{58}$ - although, of course, a case can also be made for genetic information being regarded as the most private information of all. ${ }^{59}$ While we all have moral obligations to our kin, not all such obligations are enforced by health professionals. It would be difficult to define the circumstances in which a professional should disclose genetic information without consent, however, and perhaps it is best if these circumstances are left ill-defined so that they remain truly exceptional instead of becoming applied in a routine and formulaic manner that could impact upon the trust with which patients and clients approach clinical services. ${ }^{60}$

Our findings suggest that many cases of nondisclosure arise because of the practical difficulties encountered by clients in managing the disclosure rather than from their wish not to inform their relatives. Other studies ${ }^{3}$ have highlighted that patients are often worried about how to disclose rather than whether or not it would be best to do so. The general issue of how to support families to promote the appropriate sharing of genetic information is something for the genetic counselling community to consider further. ${ }^{17}$ There may be a role for professionals to be actively involved in family disclosures in support of anxious clients. Indeed, in an earlier study of women attending a clinic with a family history of breast or ovarian cancer, one of the dissatisfactions reported by several women was the lack of support or help in informing relatives who might be at risk. ${ }^{61,62}$ Families offered followup genetic counselling services, including those provided through genetic family registers, report better preparation for discussing genetic issues with their relatives. ${ }^{23}$ We should be working on ways of helping families to communicate effectively and sensitively across the generations and should include support for this in the training of genetics professionals. ${ }^{63}$ This is likely to be much more fruitful than developing regulatory approaches to deal with the most unusual confrontations between counsellors and clients.

\section{Acknowledgements}

We thank Drs Oonagh Corrigan and Bryn Williams-Jones for helpful comments on an earlier draft of this paper. This was an unfunded study carried out by clinicians and academic colleagues while they were engaged in their regular professional activities; all the authors thank their many colleagues for the care and trouble they took in providing the data. During this study, Angus Clarke was supported in part by a grant from the Wellcome Trust.

\section{References}

1 Berkendorf JL, Reutenaeur JE, Hughes C et al: Patients' attitudes about autonomy and confidentiality in genetic testing for breastovarian cancer susceptibility. Am J Med Genet 1997; 73: 296-303.

2 European Community Huntington's Disease Collaborative Study Group: Ethical and social issues in presymptomatic testing for Huntington's Disease. J Med Genet 1993; 30: 1028-1035.

3 Wagner Costalas J, Izen $\mathrm{M}$ et al: Communication of BrCa1 and $\mathrm{BrCa} 2$ results to at-risk relatives: a cancer risk assessment program's experience. Am J Med Genet 2003; 119C: 11-18.

4 Ormond KE, Mills PL, Lester LA et al: Effect of family history on disclosure patterns of cystic fibrosis carrier status. Am J Med Genet 2003; 119C: 70-77.

5 Miesfeldt S, Cohn W, Jones S: Breast cancer survivors attitudes about communication of breast cancer risk to their children. Am J Med Genet 2003; 119: 45-50.

6 Australian Law Reform Commission and Australian Health Ethics Committee. Protection of Human Genetic Information, Issues Paper 26, 2001.

7 Bell D, Bennett B: Genetic secrets and the family. Med Law Rev 2001; 9: 130-161.

8 British Medical Association: Human Genetics: Choice and Responsibility. Oxford: Oxford University Press, 1998.

9 Forrest K, Simpson SA, Wilson BJ et al: To tell or not to tell: barriers and facilitators in family communication about genetic risk. Clin Genet 2003; 64: 317-326.

10 Wilson BJ, Forrest K, van Teijlingen ER et al: Commentary: family communication about genetic risk: the little that is known. Commun Genet 2004; 7: 15-24.

11 Skene L: Genetic secrets and the family: a response to Bell and Bennett. Med Law Rev 2001; 9: 162-169.

12 Tassicker R, Savulescu J, Skene L et al: Prenatal diagnosis requests for Huntington's disease when the father is at risk and does not want to know his genetic status: clinical, legal, and ethical viewpoints. Br Med J 2003; 326: 331-333.

13 Kessler S: Genetic Counselling-Psychological Aspects. New York: Academic Press, 1979.

14 Clarke A: Is non-directive genetic counselling possible? Lancet 1991; 338: 998-1001.

15 Sommerville A, English V: Genetic privacy: orthodoxy or oxymoron? J Med Ethics 1999; 25: 144-150.

16 Wüstner K: Ethics and practice: two worlds? The example of genetic counselling. New Genet Soc 2003; 22: 61-87.

17 Claes E, Evers-Kiebooms G, Boogaerts A et al: Communication with close and distant relatives in the context of genetic testing for hereditary breast and ovarian cancer in cancer patients. Am J Med Genet 2003; 116A: 11-19.

18 Cox SM: 'It's not a secret but.' Predictive testing and patterns of communication about genetic information in families at risk for Huntington's disease; Unpublished PhD thesis, University of British Columbia, 1999.

19 Richards MPM: Annotation: genetic research, family life and clinical practice. J Child Psychol Psychiatr 1998; 39: 291-306.

20 Skirton H: Telling the children; in Clarke A (ed): The Genetic Testing of Children. Oxford: Bios Scientific Publishers, 1998, pp $103-111$.

21 Duster T: The social consequences of genetic disclosure; in Carson RA, Rothstein MA (eds): Behavioral Genetics: The Clash of Culture and Biology. London: The John Hopkins University Press, 1999, pp $172-188$.

22 Green J, Richards M, Murton F et al: Family communication and genetic counselling: the case of hereditary breast and ovarian cancer. J Genet Counsel 1997; 6: 45-60.

23 Wright C, Kerzin-Storrar L, Williamson PR, Fryer A, Njindou A: Comparison of genetic services with and without genetic 
registers; knowledge, adjustment and attitudes about genetic counselling among probands referred to three genetic clinics. J Med Genet 2003; 39: e84.

24 d'Agincourt-Canning L: Experiences of genetic risk: disclosure and the gendering of responsibility. Bioethics 2001; 15: 231-247.

25 Sobel S: 'Do you need to know?' Genetic testing for Huntington's disease; in: McDaniel S, Hepworh J, Doherty W (eds): The Shared Experience of Illness: Stories of Patients, Families, and Their Therapists. New York: Basic Books, 1997.

26 Costalis JW, Itzen M, Malick J et al: Communication of BRCA1 and BRCA2 results to at-risk relatives: a cancer risk assessment program's experience. Am J Med Genet 2003; 119C: 11-18.

27 Featherstone K, Atkinson PA, Clarke AJ: Family and Kinship in the Era of New Genetics, Report to The Wellcome Trust 2003.

28 Richards MPM: Families, kinship and genetics; in: Marteau T, Richards MPM (eds): The Troubled Helix: Social and Psychological Implications of the New Human Genetics. Cambridge: Cambridge University Press, 1996.

29 Richards, MPM: Assisted reproduction, genetic technologies and family life; in Scott J, Treas J, Richards MPM (eds): Blackwell Companion to the Sociology of Families. Oxford: Blackwell, 2003.

30 Hakimian R: Disclosure of Huntington's disease to family members: the dilemma of known but unknowing parties. Genet Test 2000; 4: 359-364.

31 Royal College of Physicians Committees on Clinical Genetics and Ethical Issues in Medicine. Ethical Issues in Clinical Genetics. London: Royal College Physicians London, 1991.

32 Human Genetics Society of Australasia: Privacy Implications of Genetic Counselling, March 1999, http://www.hgsa.com.au/.

33 Brownsword R, Cornish WR, Llewelyn M: Law and Human Genetics: Regulating a Revolution. Oxford: Hart Publishing, 1998.

34 Laurie G: Legal and Ethical Aspects of Genetic Privacy. Cambridge: Cambridge University Press, 2001.

35 Human Genetics Commission: Inside Information: Balancing Interests in the Use of Personal Genetic Data. London: Department of Health, 2002.

36 Gilbar R: Medical confidentiality within the family: the doctor's duty reconsidered. Int J Law, Policy Family 2004; 18: 195-213.

37 Hughes C: Genetic testing for inherited breast-ovarian cancer susceptibility: the role of communication and personality characteristics; Unpublished PhD thesis, Howard University, United States, 1997.

38 Ayme S, Macquart-Moulin G, Julian-Reynier C et al: Diffusion of information about genetic risk within families. Neuromuscul Disord 1993; 3: 511-514.

39 Wertz DC, Fletcher JC: Ethics and medical genetics in the United States: a national survey. Am J Hum Genet 1988; 29: 815-827.

40 Pencarinha DF, Bell NK, Edwards JG et al: Ethical issues in genetic counseling: a comparison of M.S. counselors and medical geneticist perspectives. J Genet Counselling 1992; 1: 19-30.

41 Rhodes R: Genetic links, family ties and social bonds: rights and responsibilities in the face of genetic knowledge. $J$ Med Philos 1998; 23: $10-30$.

42 Weijer C: Family duty is more important than rights bmj.com/ egi/content/full/321/7274/1464, 2000.

43 Juengst ET: Genetic testing and the moral dynamics of family life. Public Understanding Sci 1999; 8: 193-205.

44 Bower MA, Veach PMc, Bartels DM, LeRoy BS: A survey of genetic counselors' strategies for addressing ethical and professional challengs in practice. Genet Counsel 2002; 1: 163-186.

45 Falk MJ, Dugan RB, D'Riondan MA, Matthews AL, Robin NH: Medical geneticists' duty to warn at-risk relatives for genetic disease. Am J Med Genet 2003; 120A: 374-380.

46 Dugan RB, Wiesner GL, Juengst ET et al: Duty to warn at-risk relatives for genetic disease: genetic counselors' clinical experience. Am J Med Genet 2003; 119C: 27-34.

47 Plantinga L, Natowicz MR, Kass NE et al: Disclosure, confidentiality and families: experiences and attitudes of those with genetic versus non-genetic medical conditions. Am J Med Genet 2003; 119C: $51-59$.

48 Manjoney DM, McKegney FP: Individual and family coping with polycystic kidney disease: the harvest of denial. Int J Psychiatr Med 1978; 9: 19-31.

49 Jolly A, Parsons EP, Clarke AJ: Identifying carriers of balanced chromosomal translocations: interviews with family members; in Clarke AJ (ed): The Genetic Testing of Children. Oxford: Bios Scientific Publishers, 1998, pp 61-90.

50 Järvinen $\mathrm{O}$, Aalto A-M, Lehesjoki A-E et al: Carrier testing of children for two $\mathrm{X}$ linked diseases in a family-based setting: a retrospective long term psychosocial evaluation. J Med Genet 1999; 36: 615-620.

51 Cox SM, McKellin WH: 'There's this thing in our family'. Predictive testing and the construction of risk for Huntington's disease. Sociol Health Illness 1999; 21: 622-646.

52 Downing C: Reproductive decision-making in families at risk from huntington's disease: perceptions of responsibilities; Unpublished PhD thesis, University of Cambridge, 2001.

53 Huniche L: Huntington's disease in everyday life. Knowledge, ignorance and genetic risk; PhD dissertation Center for Health, Humanity and Culture, Aarhus University, 2002.

54 France E, Gray J, Elwyn G et al: Genetic testing considerations in breast cancer patients. J Genet Counsel 1999; 8: 289-299.

55 Hallowell N, Foster C, Eeles R, Ardern-Jones A, Murday V, Watson M: Balancing autonomy and responsibility: the ethics of generating and disclosing genetic information. $J$ Med Ethics 2003; 29: 74-83.

56 Elwyn G, Gray J, Clarke A: Shared decision making and nondirectiveness in genetic counselling. J Med Genet 2000; 37: $135-138$.

57 Offit K, Groeger E, Turner S, Wadsworth EA, Weiser MA: The 'Duty to Warn' a Patient's Family Members About Hereditary Disease Risks. J Am Med Assoc 2004; 292: 1469-1473.

58 Parker M, Lucassen A: Genetic information: a joint account? BMJ 2004; 329: $165-167$

59 Boddington P: Confidentiality in genetic counselling; in Clarke A (ed): Genetic Counselling: Practice and Principles. London: Routledge, pp 223-240.

60 Clarke A: Challenges to genetic privacy; in: Harper PA, Clarke AJ (eds): Genetics, Society and Clinical Practice. Oxford: Bios Scientific Publishers, 1997, pp 149-164.

61 Hallowell N, Green JM, Statham H, Murton F, Richards MPM Recall of numerical risk estimates and counsellee's perceptions of the importance of risk information following genetic counselling for breast and ovarian cancer. Psychol, Health Med 1997; 2 : 149-159.

62 Richards MPM: Genetic counselling for those with a family history of breast or ovarian cancer. Acta Oncol 1999; 38: 559-565.

63 Lucassen A, Parker M: Confidentiality and serious harm in genetics - preserving the confidentiality of one patient and preventing harm to relatives. Eur J Hum Geneti 2004; 12: 93-97.

64 Peterson S, Watts, Koewly L: How families communicate about HNPCC genetic testing: findings from a qualitative study. $\mathrm{Am} \mathrm{J}$ Med Genet 2003; 119C: 78-86.

65 Nuffield Council on Bioethics. Genetic Screening: Ethical Issues. London: Nuffield Council on Bioethics, 1993.

66 American Society of Human Genetics Social Issues Subcommittee on Familial Disclosure: ASHG Statement: professional disclosure of familial genetic information. Am J Hum Genet 1998; 62: 474-483.

67 Genetic Interest Group: Confidentiality Guidelines. London: Genetic Interest Group, 1998.

68 General Medical Council: Confidentiality: Protecting and Providing Information. London: General Medical Council, 2000.

69 Department of Health: Confidentiality: A Code of Practice for NHS Staff (Draft). London: Department of Health, 2002. 